\title{
Negotiating Organizational Constraints: Tactics for Technical Communicators
}

Marjorie Rush Hovde, Ph.D.

Indiana University-Purdue University Indianapolis

Les communicateurs techniques travaillent dans des organismes, où les conventions et les frontières sont source de confusion pour les débutants. L'étude présentée fait état d'observations découlant d'une recherche menée sur deux lieux de travail distincts. On y décrit comment quatre communicateurs techniques utilisent diverses tactiques socio-interactives pour traiter des contraintes organisationnelles en recourant à des modeles comportementaux efficaces, moyennement efficaces et moins efficaces. Ces tactiques permettent aux communicateurs de maintenir le système d'activité de l'organisme, d'y résister ou de le modifier de façon pro-active. L'étude montre que le recours à certaines de ces tactiques permet aux communicateurs techniques de négocier efficacement avec d'autres personnes de l'organisme, particulièrement en fournissant à leurs collègues de travail des raisons convaincantes en relation avec l'organisme. Ces tactiques, qui représentent une dimension d'expertise clé pour les communicateurs techniques, intéressent les communicateurs techniques débutants, les formateurs oeuvrant en contexte universitaire et les responsables de formation au travail.

The author wishes to thank Patricia Sullivan, Jim Porter, Janice Lauer, and Rachel Spilka, the dissertation committee under whose guidance the data were originally collected. In addition, Graham Smart, his students in a Purdue University graduate seminar in Professional Writing Theory, and an anonymous Technostyle reviewer have contributed valuable insights for analyzing this material.

"You gotta know when to hold 'em

Know when to fold 'em

Know when to walk away

Know when to run."

(Don Schlitz, "The Gambler") 
Imagine the following scenario: A person is working on an undergraduate degree in technical communication and has begun an internship of writing computer manuals for a four-person software company as its first technical communicator. No standardized procedures guide the writing and revising of documentation. Existing manuals were written by salespeople in their spare time. The president is also the programmer, and he has openly stated that he hates documentation. He never records on paper the upgrades he has made to the software. The company's sole salesperson, who also serves as the trainer, knows a great deal about the software and the users, but he is seldom in the office because he trains clients at their sites. The only other employee is an office manager who also handles customers' questions about the software when they call in. Where does the new technical communicator start? How does she gather the information she needs about the software and the users? On what basis does she make decisions about the format and design of the manuals? Most importantly, how does she relate to the people with whom she works in order to produce good quality documentation?

This scenario, describing one of the situations in this study, supports Sopensky and Modrey's (1995) claim that in addition to technical communication abilities, technical communicators need procedural or "how-to" knowledge of how to interact socially within their organizations in order to improve the quality of their written products. Indeed Van Wicklen (2001) estimates that technical communicators can spend as much as one-third of their time interacting with co-workers in their organizations, facing obstacles such as "difficulty obtaining information, reticent or uncooperative engineers, canceled projects, unreasonable or unclear deadlines ... and office politics" (p. 8).

Thus while the job of a technical communicator is usually not as fraught with risk as that of the gambler mentioned in the epigram, both gamblers and technical communicators do need procedural knowledge in their contexts. In particular, apprentices (Lave and Wenger, 1991) in the field may lack judgment about when to hold, fold, walk away - or run. Consequently, awareness and use of a range of intra-organizational communication tactics may help student and apprentice technical communicators gain influence over their work.

To gain a greater understanding of such tactics, I conducted observational casestudy research in two different work sites. ${ }^{1}$ During my data-gathering, I noticed that apprentice technical communicators often had good ideas for designing documentation but did not know how to address corporate constraints that prevented them from carrying out those ideas. However, more experienced technical communicators 
who had a variety of tactics for dealing with their contextual situations, and who knew when to use appropriate social-interactional tactics, were frequently more influential than technical communicators who did not.

Below I discuss the literature in technical communication on intra-organizational communication dynamics, the design of the present study, its findings, and implications for theory, pedagogy and practice. The study takes as its point of departure two central questions: What tactics does a technical communicator need to know how to employ in dealing with others within the organization? How are the uses of these tactics related to the influence that technical communicators exhibit within their organizations?

\section{Technical Communicators and Inter-Organizational Communication Practices}

For technical communicators, the ability to communicate with co-workers in organizations is vital. In entry and mid-level positions that demand intense work with co-workers, technical communicators make decisions in situations where people may disagree and where resources are limited (Pfeffer, 1995). Therefore, technical communicators need to understand how influence works and how they can work within the constraints of organizational dynamics to exercise a measure of control over their work.

The relatively powerless positions of many technical communicators within their organizations may lead to unhappiness with their jobs. Reportedly, technical communicators express dissatisfaction with co-workers on a greater level than in other occupations, especially regarding the time and resources allocated to for their work, noting that documentation is frequently not a high priority in their organizations. Many technical communicators also indicate that they would like to have more responsibility in making decisions about their writing (Philbin, Ryan, and Friedel, 1995). A repertoire of intra-organizational communication options may help such technical communicators feel empowered to deal with workplace constraints, thus reducing their dissatisfaction.

This organizational challenge is particularly acute for apprentice technical communicators whose social-interactional tactics have been shaped largely by academic experiences. They face a daunting transition involving a high degree of "uncertainty" (Miller and Jablin, 1991) when they move into professional roles largely because they do not know how to understand and deal with internal organizational politics within their organizations (Thomas, 1995). New employees need to learn how to develop working relationships with co-workers who can assist them in their work, while not 
alienating others (Freedman and Adam, 1996). Furthermore, because typical political practices are often not overtly acknowledged (Thomas, 1995; Smart, 2000), apprentices' struggles to work effectively with colleagues may be made even more difficult.

The silence about power relationships within organizations also extends to silence in recent technical communication scholarship about how to deal with those power relationships (Thomas, 1995). The few authors who have tried to describe the complex expertise needed by technical communicators have tended to overlook organizational communication abilities (Green and Nolan, 1984; Dobrin, 1997). (Ironically, Dobrin mentions that one of the reasons he left technical communication was that "given the constraints" [p. 105], he was not doing the work he thought he should do.) Fortunately, however, a few authors do provide practical advice for technical communicators on taking organizational power relationships into account when communicating with reviewers of their documents (Hackos, 1994; Smart, 2000) or mention technical communicators' intra-organizational communication abilities tangentially (Heneghan, 1992; Raven, 1997). However, we need a rich understanding of effective tactics in many different situations.

When it is found, advice for technical communicators on communicating within organizations offers only general suggestions that one should try to effect changes largely through personal initiative (Barker, 1998; Grove, Lundgren, and Hays, 1992; Sopensky and Modrey, 1995). Van Wicklen (2001) is somewhat more aware of the complexities of organizational power relationships, but even so, she still encourages a great deal of personal initiative on the part of the technical communicators. Apprentice technical communicators certainly need personal initiative, but they also need to develop a repertoire of specific tactics for dealing with complex organizational constraints and expectations.

Two qualitative, empirical studies point to certain tactics that technical communicators need. Heneghan (1987) noted that the apprentice technical communicators in her workplace study needed intra-organizational communication abilities such as writing collaboratively and interviewing for information. In Raven's study (1992), the technical communicators observed needed to know how to negotiate the contradictions that arose when different reviewers disagreed about changes in documentation. Raven's technical communicators' strategies included: negotiating (checking with an approver, or getting the approver to conclude the change is necessary); capitulating; waiting; and escalating (making an executive decision, negotiating with other managers, verifying technical information, or seeking an arbitrator). The tactics Raven observed deal only with how to resolve differences of opinion. However, because of the dual-directional nature of how individuals interact with a system, I wished to 
look also at tactics that initiated action or reacted to non-conflict situations. Additionally, I wished to learn if technical communicators in other organizations practiced her four tactics.

Important social-interactional abilities needed by technical communicators in complex organizational situations have not been thoroughly explored. The socialinteractional tactics discerned through this study begin to build understandings of what those abilities are and how those abilities look in practice. This understanding can provide a range of options to beginners, as well as to more experienced technical communicators, as they attempt to carry out their complex work. In this study, I designed a project that would begin to shape a fine-grained picture of technical communicators' tactics for negotiating organizational constraints.

\section{The Study}

The methods and model for this study are located within the understanding of activity theory that human behavior is best studied in its contexts, as part of an activity system aimed at achieving specific goals and using tools and genres to achieve those goals. In considering the tactics that technical communicators employed, I assumed that they were influenced by and worked within the larger system. The tactics that I observed could be understood as both tools and genres of behavior that function during the processes of producing documentation. Below, I discuss my research questions, the theoretical framework of the study, and its methodology, research sites, and participants.

\section{Research Questions}

This study is located in the context of one broad question: What is the nature of procedural knowledge or expertise for technical communicators? On the basis of my reading of research literature (for instance, Green and Nolan, 1984; Grove, et al., 1992; Heneghan, 1987; Raven, 1992; Sopensky and Modrey, 1995) and on my observations of technical communicators at work, I have created a working map of abilities needed by technical communicators (Figure 1), indicating the complexity of their expertise. (This map is not intended to be exhaustive or representative of every technical communicator's situation. Rather, it represents abilities that technical communicators may need as they create documentation.)

In this article, I focus specifically on the upper right shaded quadrant of the map as I explore the questions: What does a professional technical communicator need to know how to do in dealing with others within the organization? What tactics are employed by influential technical communicators and by those with less influence? 


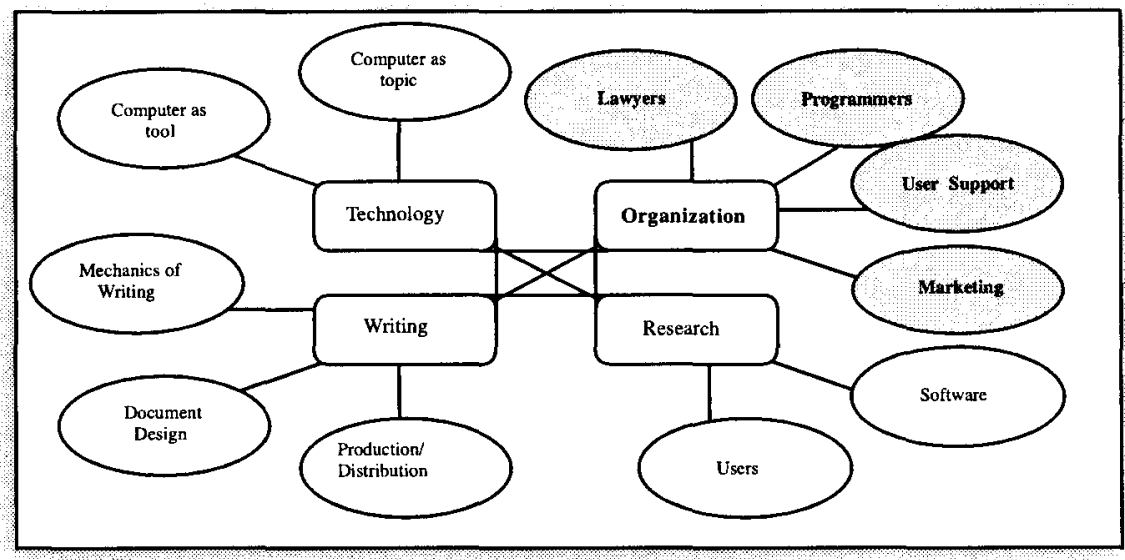

Figure 1. Technical communicators need abilities to function in four areas.

In addition, I wished to explore how activity theory could illuminate the practices of these technical communicators and how the analysis of their practices could influence the principles of activity theory.

I found these questions especially compelling after I observed the two least experienced and influential technical communicators in this study. Unlike the more experienced technical communicators, both apprentices were products of a professional writing undergraduate major with an emphasis in writing for business and industry. Yet, their specialized education in technical communication did not necessarily teach them tactics they needed for dealing with the realities of working with others in their organization. They both held many valuable ideas about the nature of effective documentation, but neither had mastered the ability to argue effectively within their organizations for major changes. They knew how to write and design documents, but they did not know how to deal with organizational constraints that influenced writing. As Pfeffer (1992) argues, "... we need to understand strategies and tactics of using power so that we can consider the range of approaches available to us and use what is likely to be effective" (p. 341). The observations in this study begin to provide such practical knowledge.

\section{Theoretical Framework}

Social-interactional practices are inextricably intertwined with the uses of power and influence. (For my purposes here, I am defining "power" as having the means to compel certain behaviors from co-workers; "influence" for me has a milder connotation, one of shaping behavior without an extensive use of force.) Technical commu- 
nicators without much knowledge of their organization may experience unproductive encounters because "Not understanding the degree to which the situation is politicized may cause a person either to use power and influence when it is unnecessary, and thereby violate behavioral norms as well as waste resources, or to underestimate the extent to which power needs to be employed, and fail in the task of implementation" (Pfeffer, 1995, p.33). This principle is played out in Raven's (1997) study in which engineers held a higher status than the technical communicators and acted to protect that status, sometimes withholding information from the technical communicators to be sure that not too many people would understand engineers' specialized information. Because previous technical communicators in the organization had lacked technical knowledge and were seen as "glorified scribes" by some engineers, these engineers were accustomed to directing the development of both the product and the documentation; they resisted the technical communicators' suggestions for how to create documents for users. These technical communicators worked in close physical proximity to engineers, so they may have followed the engineers' suggestions for changes in documentation in order to avoid insulting the engineers and thereby jeopardizing working relationships. This challenging situation is far from unusual, so technical communicators in similarly complex organizations need all the tactics they can find or devise.

One reason that political rules are often not named is that they are complex, situational, and subject to constant, albeit gradual, change as part of an "activity system." Recent proponents of activity theory argue that one should understand typical patterns of behavior in an individual by considering the entire "activity" that motivates and shapes that behavior, including the collective use physical and conceptual tools. As David Russell (1995) explains, "Activity theory analyzes human behavior and consciousness in terms of activity systems: goal-directed, historically situated, cooperative human interactions...functional system [s] consisting of a subject (person or persons), an object(ive) (an objective or goal or common task), and the tools (including signs) that mediate the interaction" (p. 53, emphasis his). Such a system operates as "a local sphere of goal-directed collaborative endeavor, where thinking, knowing, and intellectual accomplishment are mediated by a matrix of physical settings, symbol systems, analytic methods, technologies, and structured social interaction" (Smart, 2000, p. 226). This perspective can enrich our understanding of the interaction between behavior and context because activity theory "embeds consciousness in a wider activity system and describes a dynamic by which changes in consciousness are directly related to the material and social conditions current in a person's situation" (Nardi, 1996, p. 13.) In understanding the community and its rules, one can see the forces affecting the behavior of the individuals. 
Using activity theory in conjunction with empirical study (Nardi, 1996; Russell 1995, 1997) offers a researcher an "elaborated theory of context...that embraces objects and motives of collectives and their participants to explain reciprocal interactions among people..." (Russell, 1997, p.505). This approach guided this study of individuals' actions as they employed discourse tools within social contexts to accomplish specific ends. Such qualitative empirical study can lead to "grounded theory" (Berkenkotter and Huckin, 1995, p. x). As grounded theory is applied to practice, it should prove more useful because it has taken into account the entire social system in which an activity takes place.

\section{Methodology, Research Sites, and Participants}

In order to begin to answer the research questions posed above, I conducted observational case-study research in two different organizations that created user documentation for software products produced in-house. The first site, a small organization that I call B\&F Programming, employed four people. This organization produced and marketed software to a small, specialized user base. The B\&F technical communicator I studied, Sue (all names are pseudonyms), worked there in the summers and part-time during the school year. She was relatively new to the organization and revised paper manuals for their two major software products.

The second site, a larger, not-for-profit organization that I call Money Services, provided financial services to other not-for-profit organizations. Money Services' primary function was to provide these services; the software they sold to clients allowed them to provide the services more efficiently. The key informant at that site, a Technical Writer II whom I call Trish, had about five more years of experience as a technical communicator than Sue. Although Money Services had about 12 Technical Writers at the time of my data collection, I focused on three, Trish, Hanna (a Senior Technical Writer), and Faith (a Technical Writer I), as they created paper and on-line documentation for a software package that I call QuickCash.

I observed and recorded interactions of these technical communicators at work one or two days a week for a period of 10 months. As an observor, I attempted to have as little effect on the technical communicators' work as possible. The participants also kept a small notebook in which to record significant events when I was not present. I made special note of meetings and interactions during which technical communicators made decisions with co-workers. While on site, I asked the participants to talk aloud about what they were doing, as long as it did not interfere with their work. Extensive field notes, tape recordings of a few meetings, collected documents, and open-ended interviews with technical communicators and their co-workers provided additional data. 
In analyzing the data collected at the two sites, I attempted to observe what technical communicators actually did rather than relying on what they might say they did, focusing on their actual "communication behavior" (Falcione, Sussman, and Herden, 1987). Upon completion of the data collection, I analyzed and categorized the social-interactional tactics that these technical communicators used when dealing with others within the organization. I looked especially at instances in which the technical communicators took actions outside of situations covered by routine procedures. I also analyzed other factors, such as the relative experience and influence of the technical communicators within the organization.

In political situations within their organizations, these technical communicators experienced varying levels of power and influence. At B\&F, technical writing had a low priority as evidenced by the fact that Bill, the president and programmer, had not initiated the hiring of a technical communicator; Sue had called him at the beginning of a summer on the chance that he might need one. One of her biggest job challenges was to get information about the software updates from Bill, the sole programmer. She often had to find circuitous ways to complete her work; at one point, I observed her eavesdropping on a conversation Bill was having with someone else explaining his software. Sue did not perceive that she had the power to question him directly for information or to alter the typical practices of the organization. One advantage she experienced was that because there was little oversight of her work, she could determine the direction of many of her tasks and some of her documentation decisions.

Technical Writing at Money Services held a slightly stronger position within the company, even though they were housed in an office building about five miles distant from the Money Services headquarters because it was not large enough to accommodate all of Money Services' employees. (See Pfeffer, 1992, on the relationships between physical settings and power.) Several of the technical communicators commented that their situations at Money Services were better than at other places where they had worked. Several employees in other departments who worked closely with the technical communicators commented to me that they were impressed with what the technical communicators accomplished given limited resources. However, corporate culture posed barriers to ideal circumstances. For instance, the technical communicators had no direct access to external users because Marketing representatives were concerned that too much interaction with users might jeopardize accounts (Hovde, 2000). In addition, the organization's six-month software and documentation revision schedule did not permit the technical communicators to add user research to their already multitudinous tasks. Furthermore, the technical communicators could not decide by themselves how to organize manuals. Over the years, the manuals had 
been organized according to the architecture of the software because Systems Developers liked them that way, although in the middle of my data gathering, the technical communicators received permission to reorganize the manuals to be structured according to users' typical workflow. The technical communicators also had to be accountable to the Client Support Department, which was largely responsible for the distribution of the manuals.

\section{Findings}

The discussion below of these technical communicators'social-interactional tactics begins to create a picture of an important aspect of the expertise of technical communicators. While this picture will need to be tested and supplemented with further studies, nevertheless the findings provide useful insights into options available to technical communicators as they interact with people in their organizations using tactics that perpetuated, resisted, and/or shaped the activity system.

\section{Varying levels of influence among the technical communicators}

In this data gathering and analysis, I observed that the use of several socialinteractional tactics was one of the factors that affected the amount of influence that the four technical communicators observed in the study were able to employ. Below I briefly sketch a portrait of the technical communicators and then discuss the uses of each of the tactics they employed.

An Influential Technical Communicator. Hanna, as Senior Technical Writer, exercised a great deal of influence within Money Services. People both inside and outside the Technical Writing Department respected her and sought her advice. Bright, articulate, and busy, she sat on many cross-departmental planning committees for revisions to the software and the documentation. Within Technical Writing, she supervised the work of other technical communicators and served as editor of some of their documentation. (Soon after I completed my data gathering, she was promoted to Department Head when the Supervisor stepped down.)

In her use of social-interactional tactics, Hanna knew how to go along with others' decisions when necessary, even if she did not always agree with them. But she was also able to argue well for changes when needed. She frequently served as a liaison between Technical Writing and the other departments with which they needed to work, bringing information from the members of one department to those of another.

Hanna frequently agreed with the proposals of others, but she also resisted some of them. When she resisted, she usually gave a reason that others might not have thought about. These reasons frequently were based on knowledge gained through 
her interaction with others on cross-departmental committees. The technical communicators working with her usually agreed with her wishes when she presented such extra-departmental reasons.

A Moderately Influential Technical Communicator. Trish, my primary informant at Money Services, had worked at there nearly as long as Hanna had, but she did not wield the influence that Hanna did. Although Trish interacted frequently with people from other departments, she did not participate in early design decisions for revised software and documentation. Rather, the meetings she typically attended gave her opportunities only to discuss revised software specifications or participate in technical reviews of the documentation.

Trish had built an image of the documentation expectations of people in other departments and did not seem to resist their wishes very often. She generally complied with requests, especially from those whom she perceived had influence and power at Money Services. As reasons for her writing decisions, Trish frequently stated, "The Systems Developers want it this way," or "They said they wanted us to do it this way. I would change it if it were up to me." She did, however, resist more frequently within the Technical Writing Department. She did not initiate or make decisions as frequently as Hanna did, and this limited her influence on the work she was doing. In addition, the quality of the documentation sometimes suffered from her too-frequent compliance.

Trish's level of comfort in employing a variety of tactics to effect major changes in the QuickCash manuals evolved gradually through the time of my data gathering. Early in the study, at a planning meeting for the next version of documentation with Faith and Hanna, Trish brought up a list of small changes in formatting conventions that she wanted made in the QuickCash paper manuals. However as the study progressed, she was given permission from colleagues outside Technical Writing to reorganize and streamline the next version; and after that Trish listed many larger aspects of the manuals that she wished to change. Overall, Trish's typical uses of sociointeractional tactics led her to be only moderately influential in communicating with co-workers.

The Least Influential Technical Communicators. The two relatively new technical communicators whom I studied, Sue at B\&F and Faith at Money Services, exhibited even less influence in their organizations than did Trish. As a novice and the only technical communicator at B\&F, Sue needed to create documentation within an organization that did not value it highly. In contrast to Money Services, B\&F had few standard procedures for creating documentation, so Sue had to devise her own procedures and count on the cooperation of co-workers. Both Sue and Faith experienced initially what Miller and Jablin (1991) characterize as a period of uncertainty in which 
"newcomers perceive that they receive less information from those around them than they believe is needed" (p. 92). As Schein (1987) has noted, the stage of being new to an organization can be a "crucial time of learning...often painful and full of surprises" (p.158). The tactics that these apprentices employed indicate that they were still struggling to maneuver socially within their organizations.

Faith, as a Technical Writer I, suggested several innovations at Money Services, but many of them were never implemented, partly because of her limited ability to argue effectively for them with reasons that addressed organizational constraints. As a newcomer to Money Services, she had been initially assigned to revise documentation for QuickCash. Because she spent a great deal of time learning about the software well enough to document it, she had little opportunity to interact with people from outside her own department. Throughout the course of the data gathering, Faith frequently expressed frustration at how slowly traditions at Money Services changed. After working at Money Services for a year and a half, Faith complied reluctantly with creating system-oriented manuals. Although she would have preferred manuals organized by user tasks rather than by the system, she realized that tradition was strong in the Technical Writing Department and that major projects, such as revising a manual to be user-task oriented, took a great deal of time to plan. This compliance indicated that she was becoming aware of organizational constraints that prevented her from achieving an ideal. (Near the end of my data gathering, she announced that she was looking for another job, possibly one in freelance or magazine journalism.)

As mentioned earlier, both Sue and Faith were products of a professional writing undergraduate major with an emphasis in writing for business and industry; each had taken a course in writing for the computer industry, and each had more formal technical communication education than the others in this study. Both apprentices held valuable ideas about the nature of effective documentation, but neither had mastered the ability to argue effectively in their organizational contexts for major changes. As apprentices, both felt frustrated at times about not knowing their organizations well enough to be influential, a condition similar to that noted by Miller and Jablin (1991). Both technical communicators typically complied or deferred when decisions had to be made. Nonetheless, on occasion both were able to provide fresh perspectives to the traditions of each organization, as also noted in Freedman and Adam (1996).

\section{Using social-interactional tactics within the activity systems}

Given the assumption of activity theory that individuals and the culture are constantly influencing one another, I have divided these technical communicators' typical social-interactional tactics into those used by individuals to react to the culture, 


\begin{tabular}{|l|l|l|}
\hline \multicolumn{2}{|l|}{ Tactics used in reaction to the culture } & $\begin{array}{l}\text { Tactics used pro-actively to influence } \\
\text { the culture }\end{array}$ \\
\hline $\begin{array}{l}\text { Perpetuating } \\
\text { the culture }\end{array}$ & $\begin{array}{l}\text { Resisting } \\
\text { the culture }\end{array}$ & \\
\hline Agreeing & Suggesting options & Making new decisions \\
\hline Complying & Refusing & Proposing/innovating \\
\hline Acquiescing & Ignoring & Educating others \\
\hline & Postponing & \\
\hline
\end{tabular}

\section{Table 1. Social-interactional tactics have the potential to exhibit varying effects within an activity system.}

either perpetuating it or resisting it, and those used by individuals to attempt to influence the practices of the culture. (In this discussion, I do not argue that the individuals used the tactics with these intentions, but rather that the tactics had the potential to promote specific effects on the culture.)

Tactics used in reaction to the culture. Within any activity system, participants react to the expectations and demands expressed by the culture. Frequently, these technical communicators reacted to the culture in ways that had the effects of perpetuating the practices and values of the system, but they also found opportunity to resist, as discussed below.

Tactics to perpetuate the culture. The tactics discussed below, all of which had the effect of perpetuating the culture, can be divided into three types.

1. Agreeing. The technical communicators in the study often went along with requests and traditions because they were in agreement with the rationale behind them. They did their best to accommodate the requests of other departments in planning and producing the documentation. Such a high level of agreement is necessary for an organization to function, so this level of agreement is not surprising.

2. Complying. At other times, the technical communicators complied with a request, but the reason behind the compliance was often that they had not thought about reasons for or against the action. They simply did as they were told. For instance, Trish complied with organizational work processes that contributed to the creation of the manuals. She planned the documentation development processes around the schedules of the Systems Developers and the people in Systems Support who needed the manuals and on-line help in place before they could begin beta testing of the newest version of the software. 
The two least experienced technical communicators complied more frequently than the more experienced ones. At B\&F, Sue's compliance with her co-workers' requests sometimes reflected her uncertainty about principles of effective document design. For instance, Bill, the president and only programmer at B\&F, wanted topics in the manuals arranged as one-page modules, so Sue complied, even though she had to squeeze information to make it fit onto some of the pages. Once, Sue tried a different page layout to make the information fit better, but Bill did not like it, so she returned to the standard layout. In this compliance, Sue was unable to argue successfully for changes that she wished to make, but she did not display resentment when one of her ideas was not adopted.

At times, Faith complied in a way that was to her detriment. After one of Trish's reviews of the manual written largely by Faith, she made only the changes that Trish had marked. Faith did not go through the manual herself to find errors that Trish might have missed. For reasons that were not clear to me, Faith did not go above and beyond compliance in this case, which gave Trish great concern about the overall quality of Faith's manuals.

3. Acquiescing. In acquiescing, these technical communicators reluctantly went along with a request or expectation. Pfeffer (1992) has noted that many people in organizations seem to want to acquiesce, to yield authority to higher-ups. Although he decries this "passivity," at times it was necessary given the realities of competing organizational claims, especially of forces outside Technical Writing. For instance, Hanna once consented reluctantly to having the divider tabs of the QuickCash manuals printed in-house instead at an external facility that could give them a more professional look. She realized that the decision was made to reduce expenses for the company and that the standards of the Technical Writing Department had to take lower priority.

Trish and Faith also acquiesced to the Money Services' tradition that Technical Writers could not get in touch with end users, even though they believed such contact would have improved the quality of the documentation. (The Marketing Department was cautious about allowing anyone other than Marketing representatives to have contact with clients. Hence, the technical communicators knew little directly about clients and about how they used the software and documentation.) Furthermore, upper management did not budget time for technical communicators to conduct any form of user testing. Trish accepted these conditions as "given" and never proposed that the technical communicators have more direct contact with users, even though she was sure such contact would help the documentation. Faith, on the other hand, proposed from time to time that the Technical Writers find ways to find out 
more about the end users. Although some of her more ambitious plans were never implemented, she did redesign the user response card in the paper manuals, an initiative that led to an increased rate of return from users.

This acquiescence, even to co-workers' unwise decisions, should hardly surprise us. As Pfeffer (1992) has noted, "Authority is...obeyed because it is inconceivable not to. The power of leaders and bosses becomes institutionalized, and is thus not questioned or even thought about" (p. 133). Furthermore, Pfeffer notes that "social proof" is powerful in that people tend to agree with others rather than make independent judgments. Apprentice technical communicators understandably may have chosen this path of least resistance, but the more experienced technical communicators often took it as well. These technical communicators usually realized that the request was not the ideal that they would have liked, but they also realized that factors in the activity system required that they compromise their ideals. They also sometimes realized that they did not have enough influence to carry out the ideal plan. Ironically, the more they knew about the organization's goals and values, the more they were able to acquiesce when they deemed that larger goals and values were more influential than their own. However, this knowledge of the organization also allowed them to resist the culture at times, as discussed below.

Tactics that resist the culture. As Russell (1995) has argued, "activity systems are dialectical. Change is not unidirectional. It is accomplished through joint activity, whether cooperative or conflictual....The participants... appropriate (borrow and transform) the tools and object(ive)s and points of view of others, leading to changes in the means of pursuing the object(ive) of the activity system" (p. 55, emphasis his). In this vein, given the relative lack of influence that these technical communicators held within their organizations, I was surprised at how frequently they employed tactics that resisted the culture, albeit usually in indirect ways. Each of the four tactics described below had the potential to change the directions of their organizations' practices.

1. Suggesting other options. Many times, when these technical communicators did not agree with someone else's proposal, they did not say "no" directly, but instead proposed other options. This tactic can turn a culture in new directions. This tactic was most often successful when the options were feasible within the typical practices and situations of the culture. Because suggesting other options is a way of saying "no" indirectly, the technical communicators were usually able to maintain smooth working relations with co-workers while still influencing the practices of the organization.

When suggesting other options, Hanna and Trish usually gave reasons based in their knowledge of corporate constraints and their knowledge of the documentation. When the technical communicators were planning the 4.2 version of the QuickCash 
documentation, some people outside the Technical Writing Department proposed that all documentation be placed on-line. Because Hanna knew that such an approach would take several years to accomplish, she proposed instead that they send only the large manuals to the internal clients until the on-line documentation was fully implemented. In another instance, a User Support person suggested that material about professional judgment for the users might go into the manual. Trish replied that it would be difficult to include such information in the manuals, but that perhaps such material could be included in the quarterly newsletter that Electronic Services sent to clients. Had she not known about that newsletter, she may have been less able to propose a feasible option.

Although the apprentices proposed other options less frequently than did the more experienced technical communicators, occasionally insights gained from their exposure to other ideas and activity systems worked to an advantage because they were able to challenge typical practices. While participating in the planning of a new version of the QuickCash documentation, Faith suggested they eliminate the field definitions and the quick key access in one of the manuals because it was covered in another book. This proposal was accepted, as was her idea to index the paper manuals by topics rather than by chapter and section headings. Although seemingly small, these changes enhanced the usability of the manuals. The two newcomers were able to question tradition and suggest new ways to meet needs, even if these suggestions were not always implemented.

2. Refusing or resisting. Directly refusing to do what someone else in the organization has requested is probably the riskiest of the tactics that I observed these technical communicators use. This risky behavior was almost always accompanied by a reason for the refusal. The more influential technical communicators were likely to think of strong reasons to refuse. While accompanying refusals with reasons indicates the relatively powerless status of even the most influential of the technical communicators, the inclusion of a reason communicated to co-workers that the technical communicators were not refusing for arbitrary reasons, but for reasons that fit the value structures of the organizations.

Giving persuasive reasons for resistance seemed to be a part of both Trish's and Hanna's expertise as technical communicators. Simply saying "no" was not enough. In one instance, a member of another department suggested that Money Services switch from using a large three-ring binder to using a small three-ring binder to hold the manual pages. Hanna resisted this suggestion by pointing out that a smaller binder might actually involve substantial cost. At another time, people from another department suggested distributing information for clients on an electronic bulletin board. Trish cautioned against this, mentioning that clients at a previous job did not like to 
pay the communication costs for an electronic bulletin board. (This was in pre-Web days.) Their reasons seemed to be most persuasive when they took the values of the organization into account.

Despite her propensity to comply with requests from outside of Technical Writing, Trish felt more free to resist or refuse within her department. At one time, Sally, the Supervisor of Technical Writing asked Trish to write a proposal for a new project. Trish refused, stating that she was behind schedule on her regular work because she had spent the last week compiling figures for another new project. She frequently showed her ability to fit her reason to the person, knowing what reasons the other person would find persuasive.

Sometimes Trish's reasons for refusals seemed to be based more on her own standards than on what was best for the users. For instance, at one time, the technical communicators received requests from User Support to include non-software related business procedures in the QuickCash manuals. Trish argued that such knowledge was outside the typical work of a Technical Writer and that they would have to conduct additional research and interviewing in order to learn non-software information. She saw her responsibility as documenting only the software, not necessarily providing the user with non-software information. In this view, she had been influenced by the values of an organization that did not see documentation as meeting the users' non-software knowledge needs as well as training and phone support could.

The least influential technical communicators seldom refused requests directly. Instead, they used other more indirect tactics when they wished to resist the culture.

3. Ignoring. This tactic, another risky one, was seldom used. When these technical communicators ignored someone, it was usually in response to a suggestion from someone with little power. Even if these technical communicators might have wanted to ignore a request from someone in greater power, they did not do so in my observations.

The few instances of ignoring that I observed occurred in reaction to Faith, the least experienced technical communicator. For instance, while planning a new version of the QuickCash manual, Faith proposed that they send a survey to end users to see what they would like. Neither Trish nor Hanna responded to this suggestion. I do not know if they had not heard Faith, or if they had heard her and had chosen not to respond. However, conducting such a survey would have been a complex process at Money Services, involving gaining permission from many departments that would have resisted such relatively direct client contact initiated by the Technical Writers. Hanna and Trish may have elected not to take time to explain the complexities to Faith at that moment. Their lack of response may also have indicated Faith's relative 
lack of power. When impractical suggestions came from Sally, the Supervisor of Technical Writing, Trish and Hanna generally briefly and gently explained why her suggestion could not be carried out.

In most instances, suggestions from co-workers received responses, either supportive or resisting. This lack of use of the tactic of ignoring may reveal the nature of the power relationships between Technical Writing and other departments. Ignoring suggestions would have damaged the credibility the Technical Writers had worked long to build and would have strained relationships with colleagues on whom Technical Writing depended. Contrary to the observations of Lee-Ann Kastman Breuch (2001) who found that her transitional technical communication students often ignored requests from external clients, I observed no instances of Sue or Faith ignoring comments or requests from co-workers. This absence may indicate their relatively powerless position, but also may indicate that they were sufficiently aware of the practices of the workplace activity system to realize that ignoring was not typically a wise tactic.

4. Postponing or deferring. In using this tactic, the technical communicators delayed a decision and/or asked for someone else's input before making a decision. At times they even deferred the decision entirely to a co-worker. Even the least experienced technical communicators used this tactic frequently; it seemed to be one that they learned early in their careers.

Several strategic reasons may have prompted these technical communicators to postpone or defer a decision. One was that deferral allowed for greater thought and collaboration so that wise decisions could be made, especially in complex, problematic situations. As Pfeffer (1992) has argued, "Delay gives you a chance to learn more about other people's points of view and this knowledge can be employed in formulating tactics that will be more successful." (p. 227). Delay can allow time for people to think of other options and evaluate them.

As a case in point, Trish and Faith once discovered discrepancies between the software specifications and how the software actually worked. It was too late to change the software, but it also would have looked bad if an external client found the documentation to be inaccurate. Trish decided to talk to Hanna before documenting this information because, as she noted, "We've opened up a can of worms." When two competing values were in tension, Trish chose not to make the decision by herself.

Another reason for deferral was that sometimes a decision lay outside of the technical communicator's responsibilities. The most experienced and influential technical communicator, Hanna, seemed to be the one who delayed the least. One reason 
may have been that her job responsibilities did not entitle her to make those decisions. Making a decision that went beyond the boundaries of their job expectation could have landed these technical communicators in trouble.

A third reason to defer was that at times, the technical communicators did not want to take responsibility for the outcome of a decision or wanted to make sure that accountability lay elsewhere. When Hanna faced a decision that might yield negative results, she made sure that it was approved by the Technical Writing Supervisor, who would take responsibility. In addition, Hanna routinely deferred responsibility by asking upper management to sign off on the Technical Writers' planned documentation schedules, so that the technical communicators would not be accountable for missed deadlines caused by a "curve" thrown into the project by management. Thus Hanna attempted to ensure that responsibility for delayed publications lay elsewhere.

Trish frequently deferred or postponed interdepartmental decisions as a "tailcovering" tactic, such as when she asked Frank, the Supervisor of User Support, to sign off on printing redesigned manual covers. She explained, "It's his money, so having him sign off covers us." In another instance, she wrote a memo letting Sally's superiors know that a discrepancy in the numbers of QuickCash manuals planned and the number actually produced was caused by Frank having changed his mind after approving the plan. Trish wanted to be sure that they understood that the consequent depletion of inventory supplies was not her fault.

A fourth reason to delay or defer a decision was to make a point diplomatically. For instance, Frank, the Supervisor of Client Support, once suggested that all software "cascades" be listed in an appendix of the manuals, almost like a walkthrough of the software. Trish did not want to include these because it would create too much duplication to maintain, but she did not want to come across as the "bad guy." Consequently, she brought the idea up at an interdepartmental planning meeting (with Frank present) and asked the group to decide on whether or not to implement it. They decided not to.

Not being able to defer or deferring too much could have negative consequences for these technical communicators. For instance, Trish sometimes seemed unable to relinquish control as she delegated work to Faith. At times, Trish asked Faith to take responsibility for a project, but then went to relevant meetings with Faith or took the project back into her own hands if Faith was gone for a few days. Trish worked diligently and produced work of high quality, but was frequently passed over for more supervisory positions, apparently because of her weak managerial and "people" skills. In addition, Faith sometimes asked other Technical Writers to deal with issues raised by people outside of the department. Doing so may have prevented her from gaining valuable experience in working with people across the organization. 
Knowing when to defer, although it was sometimes a sign of indecision, also indicated that these technical communicators knew when to wait in order that a decision could be made thoughtfully. Deliberate delay played an important part in these technical communicators' professional knowledge. However, not handling deferral wisely may have made them less influential in the organization at times.

Tactics used pro-actively to influence the culture. Although the majority of the tactics that these technical communicators used were in reaction to the requests of other participants in their respective activity systems, these technical communicators also at times initiated actions that could potentially affect the normal practices of that system. Like the tactics for resisting, the use of pro-active tactics could lead to changes within the typical genres of behavior of the activity system.

Making new decisions. At times, these technical communicators ran into situations in which no one else had made a decision for them to follow. In those instances, they often made decisions without a great deal of consultation. Usually, these decisions were about small changes. Making decisions also entails taking responsibility for the outcomes, however, and so the least experienced and influential technical communicators often avoided making decisions, especially about major issues.

Hanna made decisions, especially decisions within the Technical Writing Department, to all more frequently than the others did, based on her knowledge of users and on her knowledge of organizational constraints. Although she often made these decisions collaboratively in discussion with Trish and Faith, this practice indicates Hanna's decisiveness, her ability to create solutions that solved several problems at once, and her influence within the company. At times, Hanna took responsibility for decisions that were potentially expensive. When Trish discovered that 600-700 manual covers were printed with the QuickCash name in a format different from the copyrighted one, Hanna made the decision to discard all of them and to print new covers.

Occasionally, Trish made decisions largely on her own about small matters within Technical Writing and within her responsibilities as a Technical Writer II. For example, when planning a new version of the manuals, she and Faith decided on their own that, in order to make the manuals concise, they would show only the shortest way to do a task. In another instance of a decision that did not involve much risk, Trish altered a routine thank-you memo to the head of the Copy Center that Supervisor, Sally, had asked Trish to ghost write after a manual was complete. Trish added her own name to Sally's and turned the thank-you into a planning memo for the next version. Trish explained that she added her name because Sally did not participate in day-to-day planning, and it would look awkward if it seemed that the time-line was coming from Sally only. Trish thought the head of the Copy Center needed the timeline. Such instances of Trish's making new decisions happened rarely during my ob- 
servations, however. She usually followed the lead of others. Avoiding responsibility for decisions about large matters also meant that she did not have opportunities to exert influence on the typical organizational practices.

Although Faith did at times participate in decision-making processes with Trish and Hanna, thus learning how and when to make decisions, it was rare that Faith or Sue made decisions on their own. The apprentices did not appear to want the individual responsibility entailed in making a decision.

Proposing/innovating. In proposing or innovating, these technical communicators were typically not reacting to a situation presented to them, as in the previously discussed tactic. Instead, they seemed to be coming up with a new idea for coworkers to consider. This tactic also differs from that of making a decision in that not all of the courses of action that these technical communicators proposed were implemented. As Pfeffer (1992) has argued, "Innovation almost invariably threatens the status quo, and consequently innovation is an inherently political activity" (p. 7). Therefore, it should not be surprising that Hanna and Trish innovated relatively more frequently than Faith and Sue, the two least experienced and effective technical communicators, especially about matters that carried a great deal of weight.

Hanna seemed to propose more freely than did any of the other technical communicators in this study. She was more inclined to initiate and give persuasive reasons, to act rather than only react. She frequently proposed new practices outside the Technical Writing Department, indicating that she knew how to deal with the power relationships of the larger organization. Although she solicited responses and input from others, she also suggested possibilities for how revised documentation could deal with problems that the others observed. Hanna's greatest source of influence, in addition to her position as Senior Technical Writer, seemed to lie in her ability to propose new ways of working. Innovation may have been less frequently observed in the other Technical Writers because, as Pfeffer (1992) argues, "organizational innovation often...involves obtaining the power and influence necessary to overcome resistance" (p. 71). Hanna demonstrated such influence by initiating requests for information from people in other departments about QuickCash users and about what should be excluded from the manuals. She proposed new formats for the manuals when the audience for them changed. These proposals provided opportunity for the typical practices of the activity system to change.

While Trish was willing to innovate in some circumstances, her work was characterized by less innovation than that of Hanna. In one instance she proposed that they make page breaks more frequent in the manuals, but such innovations were not typical for her. She worked cautiously within what she understood to be her responsibilities. Although Trish had ideas for possible directions, these ideas were often ex- 
pressed only in reaction to someone else's comments. As Pfeffer (1992) has argued, initiating can make one vulnerable, and can cause actions to be taken that cannot be easily undone. Trish apparently did not wish to take on such uncertainty and responsibility, although she did find ways to innovate in lower-risk situations.

While Faith and Sue were generally less likely to innovate than Hanna and Trish, nevertheless they were able to propose and implement several changes in the manuals that added to their usability. For instance, Sue reorganized some of the manuals into a more chronological structure, and Bill approved of the change. She also experimented with new page designs and suggested adding a glossary to one of manuals. In these innovations, she demonstrated an emerging sense of users' documentation needs and of what might meet those needs.

Faith also frequently proposed new approaches. Not all were accepted, but her proposing of them indicated that she felt free to innovate (or that she was unaware of the risks she was taking). For instance, at a planning meeting for revising the 4.2 documentation, Faith argued that on-line help should be brief, task-oriented, and without background information. This suggestion was not implemented, but her others about a new page for each task, the inclusion of a mail-back card for client responses, and an index for the manuals organized by topics rather than by headings from the text all were implemented for the 4.2 QuickCash manuals. During Faith's time at Money Services, she had begun to learn how to generate persuasive reasons for her proposals. When the QuickCash documentation team was planning to revise manuals, Faith argued for starting each new task on a new page. Hanna expressed concern that this change might make the manuals longer, but Faith countered with a prototype chapter of the QuickCash manual that she had created with each task on a new page; the section had not become significantly longer. In doing so, Faith displayed that she had learned that she needed to provide evidence to support her claim to Hanna's satisfaction.

However, Faith had not yet learned tactics for presenting or proposing ideas in interdepartmental settings, a tactic that the more influential technical communicators practiced much more frequently then she did. The apprentices' relative newness seemed to be an asset in thinking of new ways to approach their work-and one could speculate that this was because of their recent experience in other activity systems - their inability to argue effectively for some of their innovations limited the amount of changes that they could actually implement.

Educating others. At times, the technical communicators in the study, especially the more experienced ones, took advantage of opportunities to educate co-workers about the typical practices of their area of their organizations. As could be expected, they educated newer technical communicators, but they also took opportunities to 
educate people outside of the Technical Writing Department about its needs. In a sense, this tactic could be viewed as one that perpetuates the activity system, but it also can be seen as an attempt to be pro-active rather than reactive.

As Green and Nolan (1984) have argued, educating others is typically one of the tasks of more experienced technical communicators. Educating others often happened during the technical communicators' everyday tasks rather than in structured, formal settings (as in Freedman and Adam, 1996). Hanna's role as liaison gave her opportunity to educate co-workers both inside and outside the Technical Writing area. In one instance, a manager in Systems Support commented in reviewing drafts of new QuickCash Quick Reference manuals that information was not complete. Even though Faith was writing the manuals and receiving reviewer comments, Hanna called this manager and explained to her that Quick Reference manuals were intended only to give basic information. The manager's comments stopped after that call.

Hanna was able to educate and to provide reasons for explaining why a certain action might not be able to be taken. Educating another person, especially a novice to the organization, allows an insider such to "rais[e] to awareness" about what she "knows but has relegated to...her subconscious or has taken for granted" (Sutton and Louis, 1987, p. 350). Opportunities for education also may "challenge or affirm the insider's schema" (Sutton and Louis, p. 350). Hanna's ability to educate others reflected her great knowledge of the organizational climate at Money Services and provided clues to her understanding of its constraints.

Although she did so less frequently than Hanna, Trish also educated co-workers in the course of her daily work. For instance, she was able to use the QuickCash documentation structure to show other Technical Writers how to incorporate information in documentation without capturing prompts from the software, because capturing prompts was difficult and took a great deal of time. In addition, she educated Faith in how to learn about new software by reviewing specifications for a QuickCash variation and writing questions for Faith to cover in the specifications walkthroughs.

In addition, Trish frequently educated Frank, the Supervisor of User Services, who had worked for Money Services for only one-and-a-half years and at times seemed unaware of the complexities of the organization. When Frank commissioned a special Quick Reference manual, Trish educated Frank and others from User Support about the technical communicators' writing cycles, emphasizing that when a document went out for review, it was largely complete. This action seemed necessary to her because several people in Client Support wanted to make major changes in a review draft of a Quick Reference manual late in the document cycle. Her tactic of 
educating a newcomer helped to solidify her position as an insider (Sutton \& Louis, 1987 ) and may have contributed slightly to her power or influence within the organization.

Faith and Sue were not in positions from which they could educate others, as would be consistent with Green and Nolan's findings (1984). They were still in the position of being educated about the practices of their new activity systems.

\section{Implications for Practice, Theory, and Pedagogy}

The socio-interactional tactics discussed above seem consistent with two of Pfeffer's (1992) principles of working with power within an organization: understanding the various interests within the organization, and understanding why others may think the way they do. The technical communicators observed in this study did not seem to use these tactics deliberately, but rather used them spontaneously, contrary to Pfeffer's recommendation that in the process of implementing a project within an organization, one should set goals, study others within the organization, and then select appropriate tactics to get the job done. As the table below indicates, technical communicators with varying levels of influence used these tactics in different ways. How frequently the technical communicators used each tactic, especially at the varying levels of influences that each one held, reveals the practice of one highly significant aspect of their expertise.

\section{Effective and Ineffective Practices of Influence}

In this study, the effectiveness of the social-interactional tactics listed in Table 2 was influenced by factors including the person using the tactic, this person's position in their organization, and the political context in which the tactic was used.

This study indicates that knowing how to interact with co-workers is an important component of procedural knowledge/expertise for technical communicators. The tactics discerned in this study begin to provide a range of options that might help the technical communicator mentioned in the opening paragraph of this article to work within a difficult context. In naming these tactics, I hoped to put names to elements of tacit practical procedural knowledge and dispel some of the mystery about how technical communicators deal with organizational power relationships. The findings also begin to answer the research questions addressed in this study regarding how technical communicators deal with organizational constraints, how these findings relate to activity and discourse theories, and how we can use these insights in pedagogy. 


\begin{tabular}{|c|c|c|c|}
\hline Tactics & $\begin{array}{l}\text { Most influential technical } \\
\text { communicator } \\
\text { (Hanna) }\end{array}$ & $\begin{array}{l}\text { Moderately influential } \\
\text { technical communicator } \\
\text { (Trish) }\end{array}$ & $\begin{array}{l}\text { Least influential technical } \\
\text { communicators } \\
\text { (Sue, Faith) }\end{array}$ \\
\hline $\begin{array}{l}\text { 1. Agreeing/ } \\
\text { complying/ } \\
\text { acquiescing }\end{array}$ & $\begin{array}{l}\text { - Agreed when she had a good } \\
\text { reason, especially a user-based } \\
\text { reason. } \\
\text { - Agreed reluctantly sometimes, } \\
\text { given corporate constraints. }\end{array}$ & $\begin{array}{l}\text { - Agreed more frequently with } \\
\text { extra-departmental requests } \\
\text { than with in-department } \\
\text { requests. } \\
\text { - Agreed to content and design } \\
\text { wishes of people outside of } \\
\text { Technical Writing. }\end{array}$ & $\begin{array}{l}\text { - Agreed frequently, but often } \\
\text { reluctantly. } \\
\text { - Agreed at times to their } \\
\text { detriment. } \\
\text { - Acquiesced at times because } \\
\text { they were not aware of } \\
\text { alternative courses of action. }\end{array}$ \\
\hline $\begin{array}{l}\text { 2. Suggesting } \\
\text { other options }\end{array}$ & $\begin{array}{l}\text { - Felt relatively free to suggest } \\
\text { options. } \\
\text { - Based reasons on corporate } \\
\text { needs and users. }\end{array}$ & $\begin{array}{l}\text { - Suggested options less } \\
\text { frequently than Hanna. } \\
\text { - Dealt with meeting several } \\
\text { organizational needs at once. }\end{array}$ & $\begin{array}{l}\text { - Provided fresh perspectives. } \\
\text { - Often did not give persuasive } \\
\text { reasons for new ideas. }\end{array}$ \\
\hline $\begin{array}{l}\text { 3. Resisting } \\
\text { refusing }\end{array}$ & $\begin{array}{l}\text { Cited reasons for resistance } \\
\text { based on corporate needs and } \\
\text { values. }\end{array}$ & $\begin{array}{l}\text { - Refused more frequently than } \\
\text { one might have expected. } \\
\text { - Refused indirectly, } \\
\text { accompanied by a reason. } \\
\text { - Resisted user-friendly } \\
\text { innovations at times when they } \\
\text { made her job harder. }\end{array}$ & $\begin{array}{l}\text { - Refused less frequently than } \\
\text { other technical } \\
\text { communicators. }\end{array}$ \\
\hline 4. Ignoring & $\begin{array}{l}\text { Ignored others rarely, especially } \\
\text { outside of the department. }\end{array}$ & $\begin{array}{l}\text { - Ignored others rarely, especially } \\
\text { outside of the department. }\end{array}$ & $\begin{array}{l}\text { - Not observed in these technical } \\
\text { communicators. }\end{array}$ \\
\hline $\begin{array}{l}\text { 5. Postponing/ } \\
\text { deferring }\end{array}$ & $\begin{array}{l}\text { - Postponed or deferred in order } \\
\text { to shift responsibility or to be } \\
\text { certain that a decision was made } \\
\text { with sufficient thought. }\end{array}$ & $\begin{array}{l}\text { - Postponed or deferred quite } \\
\text { frequently. } \\
\text { - Postponed to avoid risk as well } \\
\text { as to make collaborative } \\
\text { decisions. } \\
\text { - Deferred especially on out-of- } \\
\text { department matters. }\end{array}$ & $\begin{array}{l}\text { - Postponed decisions at times } \\
\text { because of a lack of } \\
\text { information. } \\
\text { - Learned early in their careers } \\
\text { to postpone or defer. }\end{array}$ \\
\hline $\begin{array}{l}\text { 6. Making a new } \\
\text { decision }\end{array}$ & $\begin{array}{l}\text { - Made decisions collaboratively. } \\
\text { - Made more decisions on large } \\
\text { matters than did the less } \\
\text { influential technical } \\
\text { communicators. } \\
\text { - Made decisions based on her } \\
\text { knowledge of organizational } \\
\text { constraints. }\end{array}$ & $\begin{array}{l}\text { - Made decisions usually only } \\
\text { on small matters. }\end{array}$ & $\begin{array}{l}\text { - Usually made decisions } \\
\text { collaboratively. } \\
\text { - Made decisions mainly on } \\
\text { small matters. }\end{array}$ \\
\hline $\begin{array}{l}\text { 7. Proposing/ } \\
\text { innovating }\end{array}$ & $\begin{array}{l}\text { Proposed and innovated much } \\
\text { more frequently than the other } \\
\text { technical communicators. }\end{array}$ & $\begin{array}{l}\text { - Proposed or innovated at times, } \\
\text { but not frequently. } \\
\text { - Supported proposals with } \\
\text { reasons based on her } \\
\text { knowledge of the corporation. }\end{array}$ & $\begin{array}{l}\text { Proposed or innovated when } \\
\text { they were given freedom to } \\
\text { do so. } \\
\text { - Could not often support } \\
\text { proposals with persuasive } \\
\text { reasons. }\end{array}$ \\
\hline 8. Educating & $\begin{array}{l}\text { - Educated not only people within } \\
\text { Technical Writing, but also } \\
\text { outside it. }\end{array}$ & $\begin{array}{l}\text { - Educated mainly other technical } \\
\text { communicators or newcomers } \\
\text { from outside of the department }\end{array}$ & $\begin{array}{l}\text { - Not observed in these } \\
\text { technical communicators. }\end{array}$ \\
\hline
\end{tabular}

\section{Table 2. Tactics and influence variables among the four technical communicators.}

\section{What does a professional technical communicator need to know how to do in} dealing with others within the organization? Each social-interactional tactic that these technical communicators practiced carried with it risks and benefits that technical communicators had to assess quickly in situations of decision or change, depending on the role they held or the position held by the person with whom they were communicating. The most influential individuals were able to play various roles and improvise as circumstances arose, consonant with Hanks' (1991) observations of "mastery." 
Some of these tactics are similar to those that technical communicators used in Raven's (1992) study. Raven's categories of Waiting and Escalating could be subsumed under mine of Postponing/Deferring. Her Capitulating parallels the Acquiescing/ Agreeing described in this study. Her Negotiating can be seen as similar to Suggesting other Options. The technical communicators in this study used additional tactics, however, in situations that did not involve conflict resolution, thus giving a richer picture than that in Raven of technical communicators'options for communicating within organizations.

Although I did not do a quantitative analysis of the data, I observed that the more risky tactics such as Ignoring, Educating, Refusing, and Innovating were the least frequently used, especially by the less experienced technical communicators. This avoidance of risk is not surprising given the typical status of the technical communicators in this study. Additionally, many of the tactics were used in reaction to coworkers. Tactics that initiated action were used with less frequency. The relative status of the technical communicators in this study may not have permitted them a great deal of opportunity to initiate.

What tactics are employed by influential technical communicators and by those with less influence? Influence for an individual within an organization can come from many sources including one's job title, experience, knowledge, ability to persuade, communication tactics, and/or co-workers' perceptions of that individual. It appears that a combination of the title, tactics, and level of knowledge were primary factors affecting the influence a technical communicator had. As Pfeffer (1992) suggests, the job title is only one source of a person's influence and is not all one needs to exercise power. For instance, Money Services' Technical Writing Supervisor, Sally, by virtue of her job title, appeared to be in a position to implement improvements for her department, yet she was frequently ineffectual. I suspect this was because she overused the tactic of compliance. She sometimes initiated actions, but she seldom proposed new options. On the other hand, Faith and Sue, the least experienced and lowest in status of these technical communicators, at times were able to effect changes that, although seemingly small, improved the usability of the documentation. Thus it would appear that job titles alone do not determine technical communicators' influence; the influence may come in part from the socio-interactional tactics they employ while working within their positions

The technical communicators observed in the study needed to understand well the organizational constraints and culture in order to do their best work. Experienced technical communicators know that practices and reasoning within a corporation are Byzantine and irrational. For all of the technical communicators observed, simply using socio-interactional tactics themselves to accomplish their ends was not 
sufficient. They also had to know how to provide persuasive reasons for action. Reasons these technical communicators gave typically included 1) user needs and how they are likely to respond to texts, 2) formal conventions, 3) the desires of others within the company, and 4) the technical communicators' own time, energy, and expertise constraints. The more appropriately these technical communicators crafted their reasons to the audience, the more effective they were in arriving at good solutions to problems. The more influential technical communicators frequently adapted their reasons to the audience at hand. At times, a technical communicator gave slightly differing reasons for a single action, depending on the audience, indicating that they had learned how to ascertain what would be persuasive to different audiences. These influential technical communicators had learned to consider the input of co-workers but also to put forward their points of view in order to affect the finished documentation, as did the writers in Smart (2000). Within their activity systems, their actions were influenced by the prevailing conditions, but were not wholly determined by those conditions. The technical communicators were also, at times, able to influence the direction of their systems.

Beginning technical communicators may believe and act as if organizations will respond to arguments for taking an action simply because it appears to be a "common-sense" good idea. For instance, Faith desperately wanted to have greater contact with the end users of her documentation so that she could create manuals to meet their needs, an idea that seemed reasonable to her. But she was new enough to the corporate culture that she did not know how to work with the people in Marketing nor with tight schedules that prohibited the technical communicators from taking time for more audience research and analysis. Faith had several ideas worthy of implementing, but she did not understand the corporate culture well enough to know how to argue effectively for their implementation.

As a result of their academic backgrounds, Faith and Sue knew a great deal about what is typically thought of as technical communication; they knew how to compose and design text for the benefit of the readers. However, they were unable to employ their knowledge if someone else with more influence in the organization opposed them or if other constraining aspects of organizational culture were in play.

\section{Theories of Social Interaction and Discourse}

What can these findings contribute to activity theory and theories of discourse that explore interactions between the culture and the individual? This study begins to expand our understanding of how technical communicators negotiate within or-

ganizations that may "condition but not determine" their actions (Russell, 1997). The 
findings support the claim made in activity theory that an individual needs the resources of an organizational context in order to create documentation, but also that the individual's activities are constrained by the values and practices of that context.

Activity theorists also argue that change can happen within a culture when individuals see contradictions and act to resolve them. While the apprentices in this study were able to see many contradictions, the more experienced technical communicators were likely to ignore some of these contradictions. The study indicates, however, that individuals such as these technical communicators may have only a small impact on the practices of an activity system. At least three factors may stand in the way of change: (1) technical communicators may lack the knowledge to argue effectively for change, (2) large organizations with their multiple and complex activities may be difficult to change, and (3) levels of power may affect who can be an agent of change within a large and complex organization. Further study of technical communicators with more influence within their organizations may indicate how an activity system changes.

In addition, this study supports Kastman Breuch's (2001) contention that students moving from school settings to workplace settings may experience a clash of activity systems. Faith and Sue, as apprentices in transition from one system to another were learning the typical practices of a new activity system and experiencing dissonance when the two sets of expectations and traditions clashed.

Somewhat contrary to the claims of activity theorists, however, these technical communicators did not seem to use these tactics deliberately with a clear objective in view. Rather, as they faced new situations, they improvised ways to act or react. I seldom observed the technical communicators explaining why they chose a particular social-interactional tactic.

Questions remain about how these tactics fit into activity theory's classifications of the elements of an activity. Are the tactics "tools" that the technical communicators used to accomplish goals? As Christiansen (1996) has argued, typical tactics may be considered "tools" because they were created by those who used them, based on their motivations in their work; the tactics then guided their work. If so, these tactics can also be viewed as artifacts created by the technical communicators in context and then used as tools to allow them to function socially.

Or, are the tactics a form of "genre knowledge" regarding the production and use of documentation within an activity system? Genre knowledge can refer to an understanding of the formal conventions of discourse (Berkenkotter and Huckin, 1995) but also to "social action arising in response to perceived regularities in situations and exigencies" (Smart, 2000, p. 226). These genre rules can allow for variation within one's activities. Use of the tactics could be also be seen as knowledge of "behavioral 
genres" that suggest typical actions for a variety of situations. These "behavioral genres" may lie between "rules" and "tools" in activity theory models (Clay Spinuzzi, personal communication. March 24, 1999.) The socio-interactional tactics discussed here, whether viewed as "tools" or "behavioral genres," are worthy of study from an activity theory perspective because they mediate the technical communicators' social functioning and because the technical communicators use them for specific purposes. Understanding the tactics is part of understanding the expert practice of these technical communicators in context. The tactics are "artifacts" that combine with "actions," and both are "interwoven with each other and with the social worlds of the human beings they mediate" (Cole, 1996, p. 120). The insights of activity theory allow us to observe how the individual and the group interact and change each other, mediated by their tools. However, this study raises issues about how these technical communicators' tactics fit into activity theory models.

\section{Pedagogical Strategies}

The results of this study provide students and apprentice technical communicators with a repertoire of actions and reactions for communicating within an organization. Conscious knowledge can help one employ a variety of tactics and thus enhance one's effectiveness in the organization (Pfeffer, 1992). Without a conscious grasp of these options, apprentices may assume that their only options are either to do what they are asked to do or quit their jobs. However, awareness of these social-interactional tactics is only a starting point. Not all options will be equally effective or appropriate in all situations. Students also need to learn how to read a rhetorical situation to see which tactic may be appropriate (as indicated in Table 2) and to learn how to generate persuasive reasons appropriate for that situation. While apprentices may learn some of this ability through trial and error, beginning technical communicators who already possess a sense of options and alternatives from their prior training may feel less trapped into doing only what they are told.

How can beginning technical communicators acquire a repertoire of effective tactics? Although it may seem that "[p]roblem solving skills evolve more from using common sense and learning from past experience than from following a cookbook" (Sopensky and Modrey, 1995, p. 104), this "common sense" may be enhanced through deliberate instruction. Smart (2000) argues that "learning to play a role in an unfamiliar sociorhetorical 'game'... involves development on various levels, development that can only come from experience" (p. 245). However, the observations from this study provide options that apprentices might learn even before they gain workplace experience. Educators can provide "experience" in well-supported atmosphere that prepares novice technical communicators for their experience in organizations. 
Given the complexity of workplace culture and power relationships, technical communication students need exposure to writing problems and situations that are as "real-world" and complex as possible. Pedagogical conditions in which students under the guidance of an experienced instructor engage in collaborative, authentic tasks relating to a complex "messy" activity system hold the most promise for preparing students to experiment with the range of social-interactional tactics that they will need in the workplace (see Freedman and Adam, 1996). The pedagogical program that we seek should take into account Hanks' (1991) contention that "learning a process takes place in a participation framework, not in an individual mind" (p. 15). Involving students in that participation framework may prove valuable to their mastery. In addition, there are indications that "apprentices" who learn from interacting with each other learn practice more effectively (Lave and Wenger, 1991). This understanding counteracts the advice presented above that individuals just have to "work smarter" in order to negotiate organizational constraints. In this study, Faith often collaborated with more experienced Technical Writers and thus was exposed to the typical tactics employed by the more experienced colleagues. Sue, on the other hand, often floundered, partly because she had only an office manager to mentor her, not an experienced technical communicator. Educators and mentors may provide guided opportunities for educational interactions to take place.

Academically supported internships and job-shadowing can also provide students with valuable guidance during the time of transition from academia to the workplace. During this transition time, students need to look at all writing tasks in the context of "power and political situation variables" (Thomas, 1995, p. 467). In these settings, students can experience learning to analyze a "newly encountered domain of discourse in order to recognize goals, values, and social relationships that are significantly intermeshed with writing" (Smart, 2000, p. 246). Rather than learning through trial and error once on the job, students need deliberate training in interpersonal communication skills (Philbin, et al. 1995). Educators may wish to make the students' roles in projects similar to the entry-level positions they are likely to have immediately after graduation. Instructors need to provide guidance in making students aware of options available so that they do not always take the path of least resistance.

Students also need abilities for analyzing and adapting to the culture of their organizations, and they need to know how to effect change within those settings. Beginners who do not learn the culture of the organization, but who see suggestions from others only as individual preferences, will be less effective within an organization (Freedman and Adam, 1996). Additionally, newcomers need to understand the organization's "social system" in order to find persuasive reasons for change. (Pfeffer, 
1992). Because the technical communicators worked with many departments at Money Services, they held positions favorable to learning about the organizational culture. The most influential technical communicators needed to know not only writing processes, but also how to give co-workers persuasive reasons for what they wished to do. In addition to an understanding of general communication theory, students also need to know how to learn about the social dimension of an organizational activity system in order to generate reasons appropriate to co-workers.

\section{Future Research}

Although the socio-interactional tactics discussed here come from specific cases, they may have broader applications for students and technical communicators. Because this was a preliminary study, the following questions could profitably be answered in future research projects:

1. Do technical communicators in other organizational situations employ the socio-interaction tactics observed in this study? Are other similar tactics also used? How do varying situations affect the use of socio-interactional tactics?

2. How frequently do technical communicators of varying influence employ these tactics? How does use of these tactics lead to influence within an organization? What other sources of influence within an organization might technical communicators have?

3. How do apprentices learn and develop these tactics? How do they learn when to apply which tactic?

4. What reasons do technical communicators provide for their actions or reactions? How persuasive are those reasons with their audiences?

5. How do technical communicators in new organizations learn the organization well enough to begin to generate persuasive reasons for action?

Research attempting to answer these questions can enhance our theories of the practice of technical communication within complex social systems. From such research, we may also be able to design heuristics that help apprentices learn more quickly.

\section{Conclusion}

This study provides a basis for beginning to understand how technical communicators use social-interactional tactics within an organizational activity system, enhancing our understandings of a key aspect of the universe of expertise employed by technical communicators, as modeled in Figure 1 . Awareness of these tactics can help student and beginning technical communicators moving into new situations to gain more influence over their work, to know when to hold, fold, walk away, or run. Such 
procedural knowledge or "knowing in practice" (Lave and Wenger, 1991) can be used effectively to contribute to improving the quality of technical documents and the work lives of technical communicators.

\section{REFERENCES}

Barker, T.T. (1998). Writing software documentation: A task-oriented approach. Needham Heights, MA. Allyn \& Bacon.

Berkenkotter, C., and T.N. Huckin. (1995), Genre knowledge in disciplinary communication: Cognition/culture/power. Hillsdale, NJ: Erlbaum.

Breuch, L.M.K. (2001). The overruled dust mite: Preparing technical communication students to interact with clients. Technical Communication Quarterly, 10, (2) 193-210.

Christiansen, E. (1996) Tamed by a rose: Computers as tools in human activity. In B. Nardi (Ed.) Context and consciousness. (p. 175-198.) Cambridge, MA: MIT Press,

Cole, M. (1996). Cultural Psychology: A Once and Future Discipline. Cambridge, MA: Belknap Press.

Dobrin, D.N. (1997). Guest editorial: Why I don't. Journal of Technical Writing and Communication, 27, (2), 105-117.

Falcione, R.L., L. Sussman, and R.P. Herden. (1987). Context: Internal and external environment. In F.M. Jablin, et al. (Ed.), Handbook of organizational communication: An interdisciplinary perspective (p. 195-227) Newbury Park, CA: Sage.

Freedman, A. and C. Adam. (1996). Learning to write professionally: "Situated learning" and the transition from university to professional discourse." Journal of Business and Technical Communication, 10, (4) 395-427.

Green, M.M. and T.D. Nolan. (1984). A systematic analysis of the technical communicator's job: A guide for educators. Technical Communication, 31, (4) 9-12.

Grove, L.D., R.E. Lundgren, and P.C. Hays. (1992). Winning respect throughout the organization. Technical Communication, 39, (3) 384-393.

Hackos, J.T. (1994). Managing your documentation projects. New York, NY: Wiley. 
Hanks, W.F. (1991). Foreword. In J. Lave and E. Wenger, Situated learning: Legitimate peripheral participation. (p. 13-24). Cambridge: Cambridge University Press

Heneghan, B.B. (1987). The composing processes of computer documentation writers. Unpublished doctoral dissertation, George Mason University, Virginia.

Hovde, M.R. (1994/1995). The knowledgeable practice of computer documentation writers: Tactics for constructing user and software images and for negotiating organizational boundaries. (Doctoral dissertation, Purdue University, 1994.) Dissertation Abstracts International, 56,: 9523365A.

Hovde, M.R. (2001). "Research tactics for constructing perceptions of subject matter in organizational contexts: An ethnographic study of technical communicators." Technical communication quarterly, 10, (1), 59-95.

Hovde, M.R. (2000). Tactics for building images of audience in organizational contexts: An ethnographic study of technical communicators. Journal of Business and Technical Communication 14 (4), 395-444.

Kuutti, K. (1996). Activity theory as a potential framework for human-computer interaction research. In B. Nardi (Ed.) Context and consciousness: Activity theory and human-computer interaction. (pp. 17-44). Cambridge, MA: MIT Press.

Lave, J., and E. Wenger. (1991). Situated learning: Legitimate peripheral participation. Cambridge University Press, Cambridge.

Miller, V.D., and F.M. Jablin. (1991). Information seeking during organizational entry: Influences, tactics, and a model of the process. Acaderny of Management Review, 16, 92-120.

Nardi, B. (1996). Context and consciousness: Activity theory and human-computer interaction. MIT Press; Cambridge, MA,.

Philbin, A.I., A.M. Ryan, and L. Friedel. (1995). How technical communicators feel about their occupation: Facets, attitudes, and implications for the future of the profession. Journal of Technical Writing and Communication, 25, (3), 303320.

Pfeffer, J. (1992.) Managing with power: Politics and influence in organizations. Boston, MA: Harvard Business School Press. 
Raven, M.E. (1992). Analyzing and adapting to multiple audiences: A study of two writers in the computer industry. Unpublished doctoral dissertation, Rensselaer Polytechnic Institute, New York.

Russell, D.R. (1997). Rethinking genre in school and society. Written Communication 14, 504-54.

Russell, D.R. (1995). Activity theory and its implications for writing instruction. In J. Petraglia (Ed.) Reconceiving writing, rethinking writing instruction (pp. 5177). Erlbaum: Mahwah, NJ.

Schein, E.H. (1987). Individuals and careers. In J.W. Lorsch, (Ed.), Handbook of organizational behavior (p. 155-171). Englewood Cliffs, NJ: Prentice Hall/ Simon \& Schuster.

Sopensky, E. and L. Modrey. (1995). Survival skills for communicators within organizations. Joumal of Business and Technical Communication, 9, (1) 103-115.

Smart, G. (2000). Reinventing expertise: Experienced writers in the workplace encounter a new genre. In P. Dias, A. Paré, and M. Farr (Eds.) Transitions: Writing in Academic and Workplace Settings (pp. 223-252). Hampton Press. .

Sutton, R.I., and M.R. Louis. (1987). How selecting and socializing newcomers influences insiders. Human Resource Management, 26, 347-361.

Thomas, S.G. (1995). Preparing business students more effectively for real-world communication. Journal of Business and Technical Communication, 9, (4) 461474 .

Van Wicklen, I. (2001). The tech writer's survival guide: A comprehensive handbook for aspiring technical writers. Facts on File Checkmark: New York, New York. 